\title{
Harold Pinter X Prémio Europa para o Teatro
}

\section{Paulo Eduardo Carvalho}

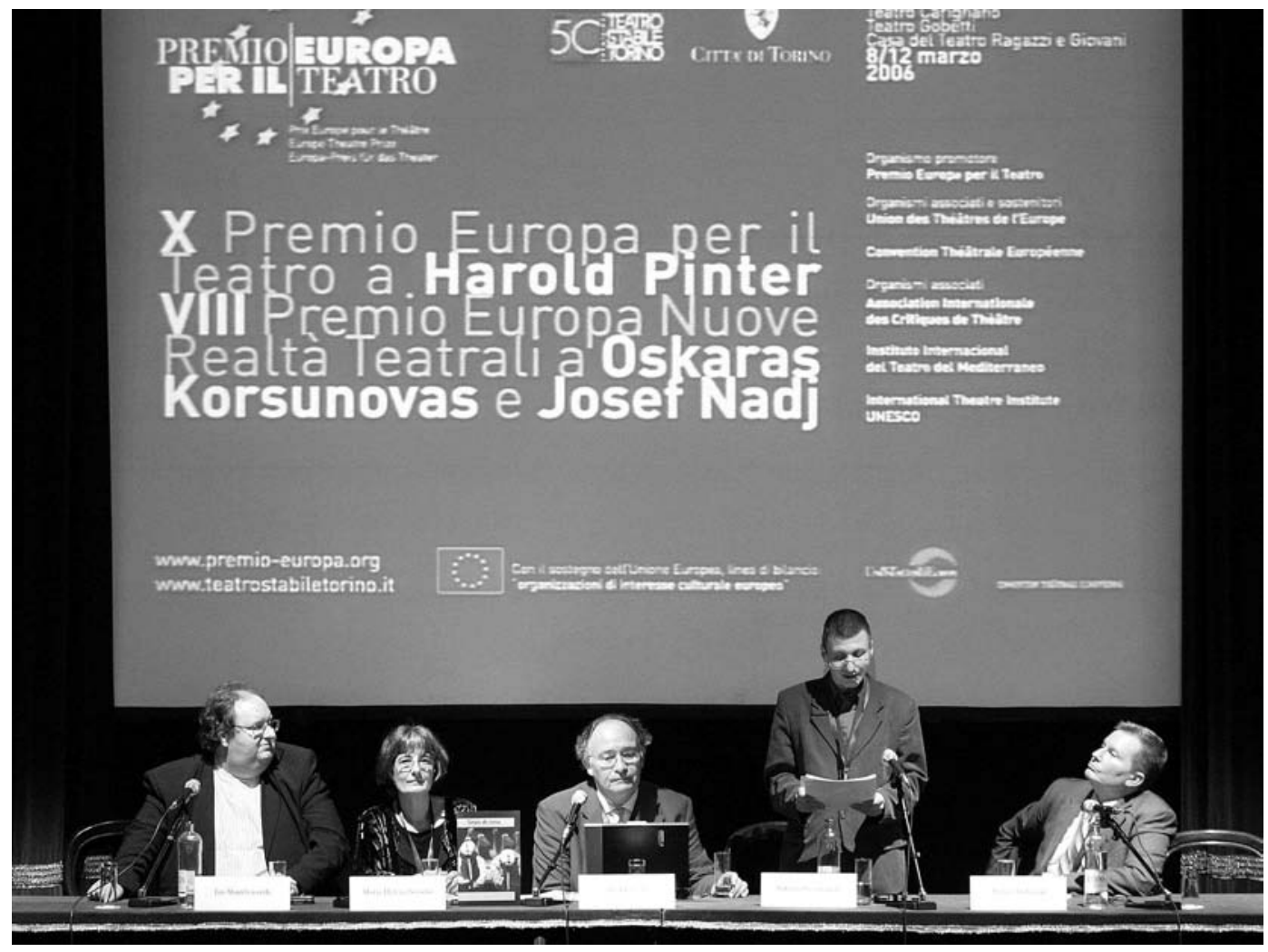

Painel de participantes no XXII Congresso da AICT: lan Shuttleworth, Maria Helena Serôdio, lan Herbert, Nikolai Pesochinsky e Porter Anderson, Teatro Gobetti, Turim 9 de Março de 2006, fot. Giorgio Sottile.

Ultrapassando uma suspensão forçada de cinco anos, o Prémio Europa para o Teatro conheceu este ano a sua décima edição, com a distinção atribuída a Harold Pinter. Anunciado em 2001, mas só finalmente entregue na cerimónia realizada em Turim, no dia 12 de Março de 2006, este prémio junta-se assim às muitas distinções de que, nos últimos anos, o escritor foi objecto, como o Prémio de Poesia Wilfred Owen, o Prémio Franz Kafka e, sobretudo, o Prémio Nobel da Literatura, anunciado em Outubro de 2005. Recorde-se que tal atenção tem sido acompanhada por uma estimulante agitação editorial, que inclui não só a reedição actualizada de Various Voices: Prose, Poetry, Politics 1948-2005, mas também a publicação de novos estudos que têm contribuído para um mais amplo conhecimento de uma obra tão intensa quanto complexa, de que são exemplo o comovente pequeno volume publicado pela Faber em 2000, Harold Pinter: A Celebration, o mais informativo Cambridge Companion organizado por Peter Raby, o Casebook organizado por Lois Gordon, Pinter at 70, ambos de 2001, o exaustivo estudo de Steven $\mathrm{H}$. Gale dedicado aos argumentos para cinema, Sharp Cut: Harold Pinter's Screenplays and the Artistic Process, em 2002, e, mais recentemente, Pinter in the Theatre, organizado por lan Smith, e About Pinter: The Playwright and the Work, de Mark Batty, dois trabalhos claramente apostados na exploração da fortuna cénica das obras do dramaturgo - algo de idêntico ao que, de forma naturalmente menos elaborada, a revista dos Artistas Unidos conseguiu fazer no seu n. 8 , ao recolher testemunhos de diferentes criadores ligados à tradução, encenação e representação de Pinter em Portugal. Aliás, também entre nós, e para além da montagem de diversos espectáculos, temos assistido ao aparecimento de algumas importantes novidades editoriais, infelizmente nem sempre tão cuidadas como seria de esperar, com a publicação, em 2002, de dois volumes reunindo dezoito das suas peças e as iniciativas mais recentes de Guerra e A teia, já com a tradução portuguesa do discurso do Nobel.

Criado em 1986, com o patrocínio da União Europeia, e atribuído pela primeira vez em 1987, o Prémio Europa para o Teatro destina-se a distinguir "personalidades ou 
Galardoados com o

Prémio Europa para Teatro:

Ariane Mnouchkine e o

Theâtre du Soleil, Peter

Brook, Giorgio Strehler,

Heiner Müller, Rober

Wilson, Luca Ronconi, Pina

Bausch, Lev Dodin, Miche

Piccoli e, agora, Harold

Pinter.

${ }^{2}$ Galardoados com o Prémio Novas Realidades Teatrais: Anatoli Vassiliev, Giorgio Barberio Corsetti Els Comediants, Eimuntas

Nekrosius, Theeâtre de Complicité, Carte BlancheCompagnia della Fortezza, Christoph Marthaler, Roya Court Theatre,

Theatergroep Holland

Thomas Ostermeier, Societas Raffaello Sanzio, Heiner Goebbels, Alain Platel e Les Ballets C. de la

B. e, em 2006, Oskaras Korsunovas e Josef Nad

${ }^{3}$ Entre os criticos que apresentaram

comunicação estiveram:

Nikolai Pesochinsk

(Academia Teatral de

Sampetersburgo), lan

Shuttleworth (do Financial

Times, actual editor de

Theatre Record), Porter

Anderson (da CNN) Maria Helena Serôdio (em representação da Sinais de

cena e da APCT).

${ }^{4} 0$ Prémio Europa é já

responsável por um número considerável de publicações, dedicadas à

obra dos premiados: GII

anni di Peter Brook;

Giorgio Strehler o la

passione teatrale; Heiner Müller: riscrevere il teatro Roberto Wilson o il teatro del tempo; Luca Roncon: la ricerca di um método; Sulle tracce di Pina Bausch.

Organizados por críticos investigadores como Georges Banu, Franco Quadri ou Renzo Tian, estes volumes incluem também secções especiais

dedicadas ao Prémio Novas Realidades Teatrais instituições teatrais que tenham contribuido para a realização de acontecimentos culturais determinantes para a compreensão e conhecimento entre os povos", e conta já com uma prestigiada lista de galardoados'. Em 1989, foi criado, em paralelo, o Prémio Novas Realidades Teatrais, que já contemplou diversos criadores e projectos teatrais ${ }^{2}$. 0 júri para esta edição foi constituido, como habitualmente, por personalidades da cultura e das artes, críticos e operadores culturais, representantes do mundo teatral europeu e, ainda, o secretário-geral e representantes dos organismos associados: Renzo Tian (secretário permanente), Georges Banu (presidente honorário da AICT), Daniel Benoin (director do Teatro Nacional de Nice e presidente da Convenção Teatral Europeia até 2005), Michael Billington (crítico do The Guardian), João Carneiro (o nosso colega, crítico do Expresso), Bernard Faivre d'Arcie (director do Festival de Avinhão até 2002), Renata Klett (crítica e directora de Festival, em Berlim), Soila Lehtonen (crítica finlandesa do Aamulehti), Eli Malka (director da União dos Teatros da Europa), José Monléon (director do Instituto Internacional de Teatro do Mediterrâneo e da revista Primer Acto), Franco Quadri (crítico do La Repubblica), Tatiana Proskournikova (critica e investigadora de teatro russa, entretanto, já falecida) e lan Herbert (presidente da Associação Internacional de Críticos de Teatro).

Forçadamente desalojado de Taormina, onde se realizaram todas as edições anteriores, este Prémio Europa acabou por contar com a colaboração preciosa do Teatro Stabile de Turim (dirigido por Walter Le Moli) e da própria autarquia, empenhada num esforço notável de recuperação cultural e urbanística de uma cidade durante décadas dominada pela indústria automóvel, entretanto, em processo acelerado de desactivação. A iniciativa albergou um número considerável de iniciativas, entre reuniões, congressos (caso do XXII Congresso da AICT, dedicado à discussão do papel da crítica no mundo actual ${ }^{3}$ ), colóquios simples conversas públicas com criadores (Luca Ronconi, Lev Dodin, Josef Nadj) e espectáculos. Registem-se duas propostas muito diversas de Oskaras Korsunovas: a imaginativa adaptação de O Mestre e Margarida, de Mikhail Bulgakov, e a decepcionante encenação de No papel da vítima, dos irmãos Presniakov. Do ciclo previsto de cinco espectáculos encenados por Luca Ronconi, sob o título inspirador de Amanhã, só foram apresentados três, com destaque para um tão arrojado como amaneirado Troilo e Cressida, de Shakespeare, e para a poderosa reflexão proposta por 0 silêncio dos comunistas, a partir do texto de Vittorio Foa, Miriam Mafai e Alfredo Reichlin.

Mas, naturalmente, o conjunto maior de iniciativas prendeu-se com a distinção conferida a Harold Pinter, que tem com Itália uma história recheada de muitos e marcantes episódios, tanto tormentosos - como, em 1973 a ousadamente erótica encenação de Há tanto tempo, por Luchino Visconti, que despertou a indignação do autor como de expressivo reconhecimento, desde um prémio de carreira, em Roma, em 1993, passando pelo convite para encenar Cinza às cinzas em Palermo, em 1997, até aos dois doutoramentos honoris causa atribuidos pelas Universidades de Florença, em 2001, e Turim, em 2002. 0 prestígio italiano de Pinter chegou mesmo a envolver, em finais dos anos noventa, avançadas negociações para que o dramaturgo assumisse a direcção do Teatro Stabile de Turim, hipótese que acabaria, contudo, por não se concretizar

A principal iniciativa desta edição do Prémio Europa foi a organização de um vasto colóquio, Pinter: Paixão, Poesia e Politica, de que foi responsável o seu biógrafo Michael Billington, em colaboração com Michela Giovannelli e Gianfranco Capitta (autor, com Roberto Canziani, de Harold Pinter: Scena e potere, um estimulante estudo recentemente publicado pela Garzanti). Talvez demasiado genéricas nas abordagens propostas, teremos a possibilidade futura de consultar as diversas contribuições apresentadas quando, à imagem do que tem acontecido em edições anteriores, elas forem publicadas em forma de livro ${ }^{4}$. A obra do dramaturgo foi também ponto de partida para dois espectáculos muito diversos, nos seus pressupostos e consequência. Sob o título comum de $A$ nova ordem mundial, Roger Planchon reuniu a quase totalidade das peças mais obviamente políticas de Pinter - justamente aquelas em que a metáfora cede lugar a uma mais directa presentificação do horror, embora sem nunca abandonar a centralidade das preocupações com a linguagem, desde a perversão envolvida no seu uso até à sua totalitária supressão - quase todas elas recentemente representadas em Portugal: Precisamente, Um para o caminho, Lingua da montanha, Tempo de festa, A nova ordem mundial e Conferência de imprensa. Reforçado por, ao que parece, um escasso tempo de preparação, o resultado revelou-se como a mais desastrosa homenagem ao distinguido por esta edição do Prémio Europa: uma abordagem cénica superficial, trivializante, apostada em tornar explícito e vulgar aquilo que em Pinter é, sempre, ambíguo e inquietante.

Completamente distinta foi a experiência de Pinter: Peças, Poesia e Prosa, uma sóbria e eficaz leitura de textos, dirigida por Alan Stanford e produzida pelo Gate Theatre, de Dublin, numa iniciativa promovida pelo enérgico Michael Colgan, igualmente responsável, em 2005, pela produção de A paisagem Pinter - uma selecção das peças, da prosa e da poesia, que terá estado na origem da proposta apresentada em Turim - e pela leitura encenada de Celebração, com interpretação de Charles Dance, Janie Dee, Jeremy Irons, Joana Lumley, Michael Gambon, Penelope Wilton e Stephen Rea. Com invulgar talento e dignidade, quatro destes actores - Dance, Irons, Gambon e Wilton, todos eles associados a algumas das mais marcantes produções das peças e argumentos para cinema do escritor - deram voz a uma magnífica selecção de textos, entre breves narrativas, trechos das peças e poemas, nomeadamente alguns daqueles que se encontram em 

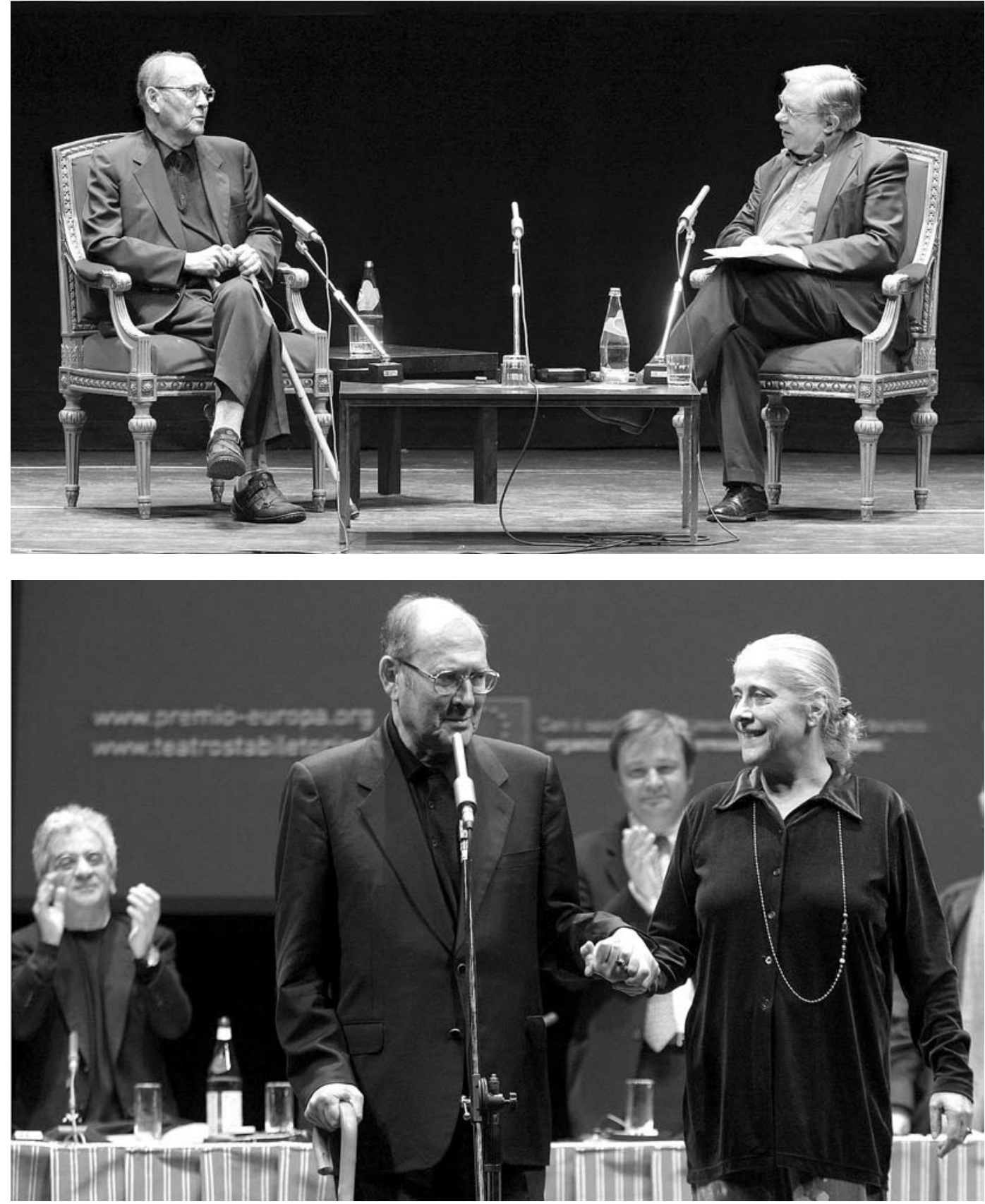

Guerra (Pinter 2005c), como "Encontro", "Previsão do tempo", "Futebol americano" - o infamemente famoso poema, de 1991, sobre a primeira guerra do Iraque, cuja publicação foi recusada por diversos jornais ingleses, numa interpretação arrebatada de Michael Gambon, que gritou o "Aleluia!" da abertura com a mais obscena jactância -, "Morte", ou ainda "Células de cancro" e um tocante tributo "À minha mulher". A selecção revelou-se plenamente ilustrativa das riquíssimas e variadas características do universo pinteriano: o seu invulgar realismo psicológico, o humor seco e sofisticado, o imperativo político de múltiplos cambiantes, a fascinante capacidade evocativa, a lúcida percepção da linguagem como arena para os mais determinantes conflitos de poder e, sobretudo, a pulsão lírica de muitos dos seus textos, claramente traduzida na música estranha das repetições, pausas e elipses de um discurso só aparentemente quotidiano. A mais extraordinária e produtiva consequência deste exercício terá sido, justamente, a afirmação do talento poético de toda a criação literária de Pinter.

Entre todas estas iniciativas, as duas aparições públicas de Pinter terão constituido, sem dúvida, os momentos mais comoventes. No dia 11 de Março, ao final da manhã, no palco do belo espaço do Teatro Carignano, durante cerca de meia hora, o dramaturgo respondeu a perguntas colocadas por Michael Billington. Aquele "algo de estranhamente beckettiano" (Billington 2005), que o crítico teatral identificara na mensagem gravada em vídeo enviada para a cerimónia do Nobel, prolongou-se nesta primeira aparição: um corpo frágil, apoiado numa bengala, habitado por uma consciência lúcida e servido por uma voz arranhada. De tão perturbadoramente real e verdadeira, a imagem impôs-se como profundamente teatral. Reproduzida três dias mais tarde nas páginas do The Guardian, a entrevista encerra um conjunto breve mas emocionante de declarações sobre os acontecimentos
Harold Pinter

e Michael Billington à conversa, Teatro Carignano, Turim, 11 de Março de 2006 fot. Giorgio Sottile.

Harold Pinter

Alessandra Serra na cerimónia de entrega do X Prémio Europa para o Teatro, Teatro Carignano, Turim, 11 de Março de 2006, fot. Giorgio Sottile. 
Jeremy Irons em Pinter: Peças,

poesia e prosa,

enc. Alan Stanford, prod. Gate Theatre Dublin, Teatro Cargignano, Turim,

12 de Março de 2006, fot. Giorgio Sottile.

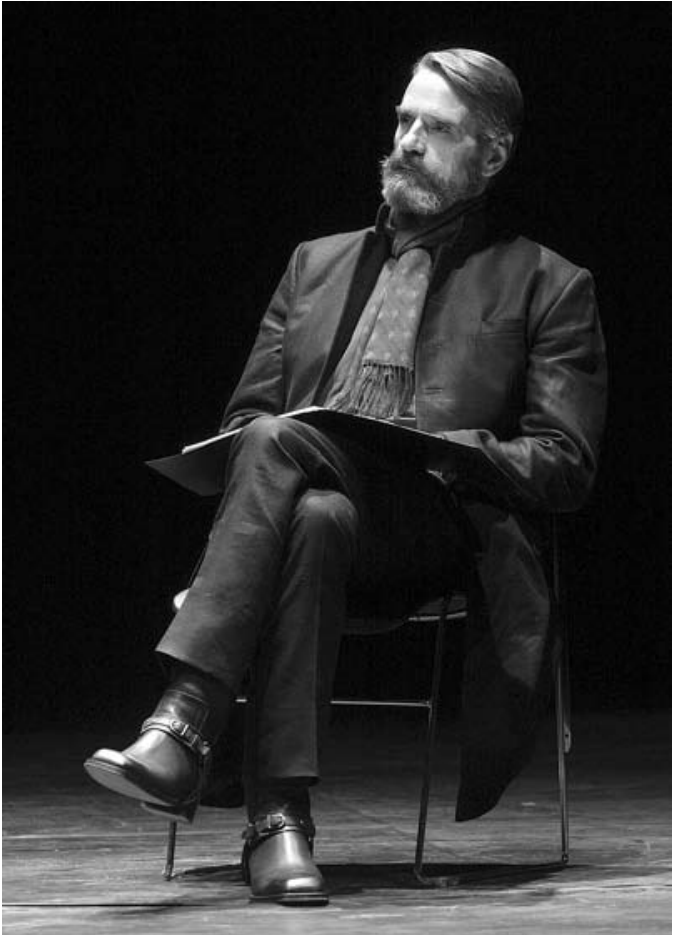

deve-se ao facto de tocarem uma corda universal. E o que todos reconhecemos é que vivemos num mundo de medo e de ansiedade apenas aliviado pelas memórias de alegrias passadas. Pinter fala ao público do mundo inteiro e às gerações vindouras, o que faz dele um laureado ideal para o Prémio Europa.

Pinter agradeceu, apoiado pela sua tradutora italiana Alessandra Serra, fazendo novo e comovente apelo à lucidez e à consciência política europeia, contra aquilo que não se cansa de apresentar como as múltiplas e sucessivas manifestações do agressivo neo-imperialismo norte-americano, recuperando a postura da sua conferência do Nobel: "Estou convicto de que, apesar dos enormes obstáculos existentes, se nós, cidadãos, tivermos uma determinação intelectual feroz, estóica, inquebrantável, conseguiremos definir a verdade real das nossas vidas e das nossas sociedades - e essa é uma obrigação crucial que nos diz respeito. É mesmo imperativa" (Pinter 2006a: 39). Embora, já então, o escritor tenha tido a inteligência de separar a necessária ambivalência da arte do seu dever como cidadão de perguntar "o que é falso e o que é verdade", não deixa de sobreviver algo de ligeiramente perturbador nesta mais recente atitude do mesmo dramaturgo que, em 1962, recusava tão ostensivamente o papel de "profeta" que alguns pareciam exigir-lhe: "Avisos, sermões, admonições, exortações ideológicas, juízos morais, problemas definidos com soluções já incluídas; todas estas coisas podem acampar sob a bandeira da profecia. A atitude por detrás deste tipo de coisa pode ser resumida numa frase: 'Estou a avisar-vos!'" (Pinter 2005b: 22). Pinter reafirmava, então: "porque a 'realidade' é uma palavra forte e firme, tendemos a pensar, ou a desejar, que o estado a que ela se refere é igualmente firme, definido e inequívoco. Não parece que seja e, na minha opinião, não é pior nem melhor por isso" (Ibidem). Talvez seja um sinal dos tempos verdadeiramente dificeis que vivemos o facto de o dramaturgo que sempre mostrou 


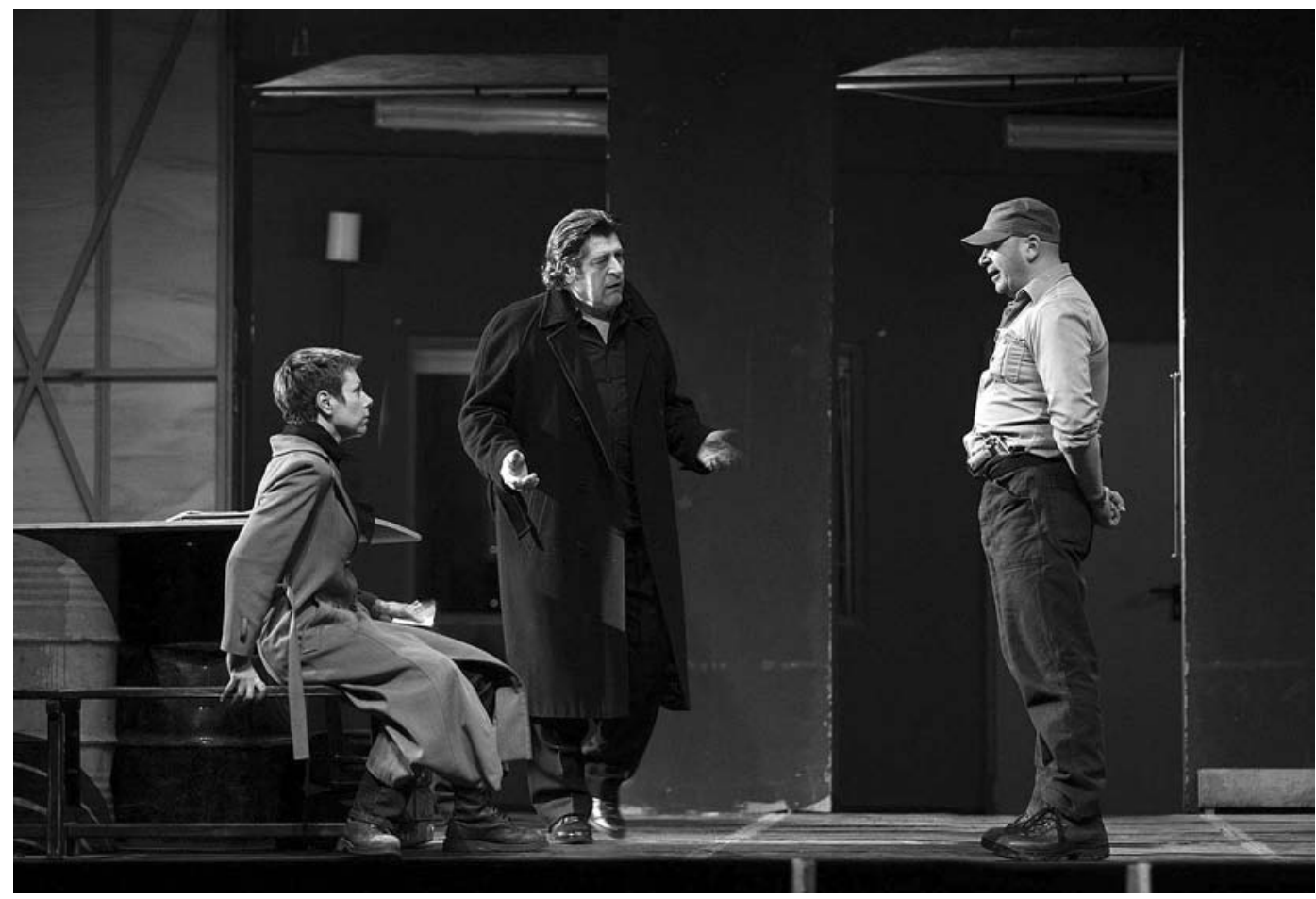

A nova ordem mundial, de Harold Pinter, enc. Roger Planchon, Teatro Gobetti, Turim, 10 de Março de 2006, fot. Giorgio Sottile.

uma tão singular consciência da responsabilidade da obra de arte para consigo mesma parecer agora entregar-se, tão desesperadamente, à simplificação da denúncia "profética", assumindo justamente o papel do escritor relativamente ao qual sempre mostrara tantas cautelas: "o escritor que avança as suas preocupações para que as abracem, que não vos deixa qualquer dúvida sobre o seu valor, a sua utilidade, o seu altruísmo, que declara que o seu coração está no sítio certo e se assegura que pode ser visto completamente" (/bidem: 23). Não está, aqui, em causa a extraordinária coerência artística de Harold Pinter, amplamente demonstrada pela articulação perfeita da sua visão artística com a sua consciência política, mas tão só a manifestação inquieta daquilo que pode resultar como uma revisão enfraquecida do papel do teatro, enquanto arte, no nosso mundo actual.

Será talvez levar longe demais algumas coincidências factuais, mas não deixa de ser tentador registar que a atribuição deste prémio a Harold Pinter ocorreu a escassos dias do centenário de um outro escritor que ele lia desde o longínquo ano de 1949 e que ele próprio apresentava, em 1954, como "o mais corajoso e implacável que ai anda" (Pinter 2005a: 58). Refiro-me a Samuel Beckett, que, como Pinter, nos legou um conjunto de textos e de poemas cénicos tão mais poderosos quanto criados sempre de acordo com um elevado sentido de exigência para com uma visão artística e um entendimento singular da humana condição.

\section{Referências bibliográficas}

AA. W. (2000), Harold Pinter: A Celebration, London, Faber and Faber. AA. W. (2003), "Sobre Harold Pinter: 0 ciclo dos Artistas Unidos, Pinter em Portugal (e noutros palcos)", Artistas Unidos Revista, n. 8, Julho, pp. 70-125.

BATTY, Mark (2005), About Pinter: The Playwright \& the Work, London, Faber \&t Faber.
BILLINGTON, Michael (1996), The Life and Work of Harold Pinter, London, Faber and Faber.

- - (2005), "Passionate Pinter's Devastating Assault on US Foreign Policy", The Guardian, 8 de Dezembro.

CANZIANI, Roberto / CAPITTA, Gianfranco (2005), Harold Pinter: Scena e potere, Milano, Garzanti.

GALE, Steven H. (2002), Sharp Cut: Harold Pinter's Screenplays and the Artistic Process, Lexington, University Press of Kentucky.

GORDON, Lois (ed.) (2001), Pinter at 70: A Casebook, New York and London, Routledge.

PINTER, Harold (2002), Teatro I [0 quarto, Feliz aniversário, 0 serviço, 0 encarregado, A colecção, 0 amante e 0 regresso a casa] e Teatro II [Paisagem, Há tanto tempo, Monólogo, Terra de ninguém, Traições, Victoria Station, Um para o caminho, Lingua da montanha, A nova ordem mundial, Cinza às cinzas, Comemoração e Cinco sketches], trad. Alcides Estrela, Artur Ramos, Berta Correia Ribeiro, Jaime Salazar Sampaio, João Saboga, Francisco Frazão, Francisco Luis Parreira, Graça P. Corrêa, Jorge Silva Melo, José Maria Vieira Mendes, Luis Fonseca, Paulo Eduardo Carvalho e Pedro Marques, Lisboa, Relógio d'Água.

- - (2003), "Londres" [excerto de Os anões e poemas], trad. Pedro Marques e Jorge Silva Melo, Tabacaria, n. ${ }^{\circ}$ 12, Outono, pp. 89-109.

- - (2005a), "Samuel Beckett" [1954], in Various Voices: Prose, Poetry, Politics 1948-2005, London, Faber and Faber, p. 58.

- - (2005b), "Writing for the Theatre" [1962], in Various Voices: Prose, Poetry, Politics 1948-2005, London, Faber and Faber, pp. 20-26.

- - (2005c), Guerra / War, trad. Pedro Marques, Jorge Silva Melo e Francisco Frazão, Vila Nova de Famalicão, Quasi.

- - (2006a), "Arte, verdade e politica", trad. Francisco Martins Rodrigues, in A Teia, Lisboa, Dinossauro Edições, pp. 11-40.

- - (2006b), "'I've Written 29 Damn Good Plays. Isn't that Enough?"' entrevistado por Michael Billington, a 11 de Março de 2006, no palco do Teatro Carignano, Turim, The Guardian, 14 de Março.

RABY, Peter (ed.) (2001), The Cambridge Companion to Harold Pinter, Cambridge, Cambridge University Press.

SMITH, lan (ed.) (2005), Pinter in the Theatre, London, Nick Hern Books. 